\title{
139. A Note on Possible Close Linkage between the Ii Blood Locus and a Congenital Cataract Locus*)
}

\author{
By Hideo Yamaguchi,**) Yasuto OKUbo,***) \\ and Masayoshi TaNaKA***) \\ (Comm. by Ren Kimura, M. J. A., Oct. 12, 1972)
}

Recently, we came across the first Japanese "i" blood family, Sug. (Yamaguchi et al., 1970) ${ }^{1)}$ (Fig. 1). Since then, three more families with such rare blood group have been discovered by us (Figs. 2-4). All the propositi of the four families (Sug., Oka., Hay., and Yama.) were detected due to difficulty in ABO-groupings in a serological survey of volunteer donors. Each family had two members of " $i$ " blood with varying titers of anti-I in serum. To our surprise, all the eight " $\mathrm{i}$ " blood persons (the propositi and their siblings) were found to have complaint of poor vision due to a congenital cataract, while their remaining seven siblings tested were normal both in blood group and vision. There were no relationships

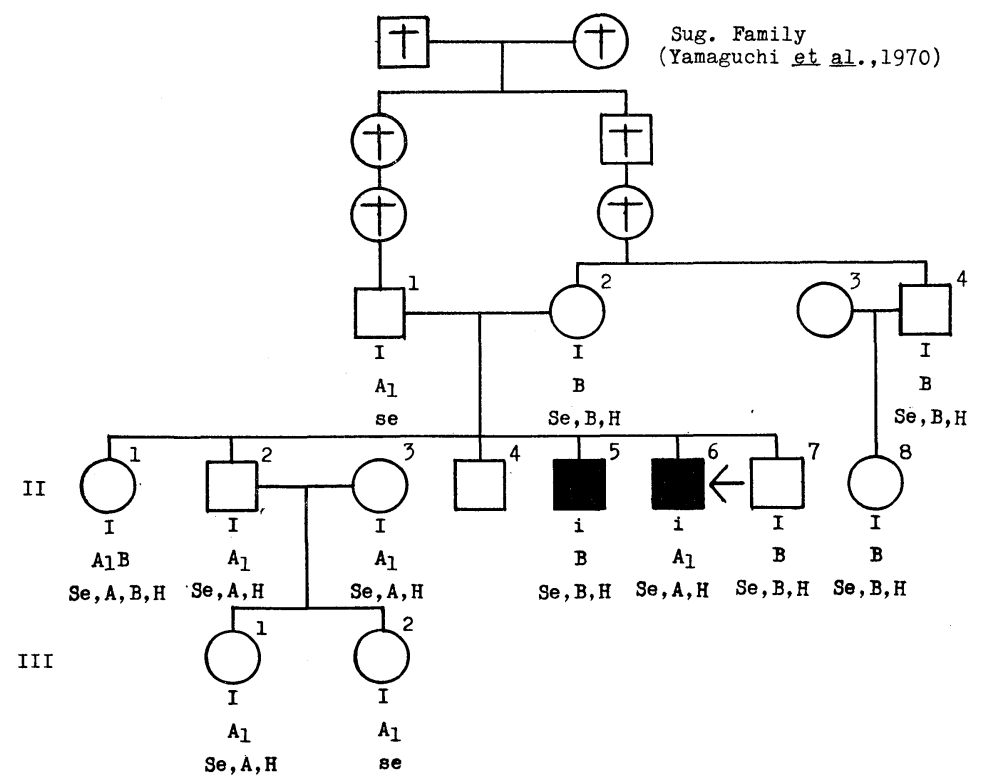

Fig. 1

*) This note is dedicated to the late Professor Taku Komal, M. J. A.

**) Osaka Red Cross Hospital and Osaka Red Cross Blood Center, Osaka, Japan.

***) Osaka Red Cross Blood Center, Osaka, Japan. 


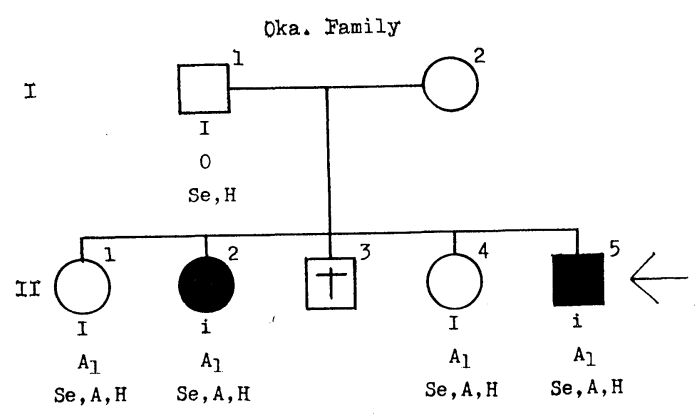

Fig. 2

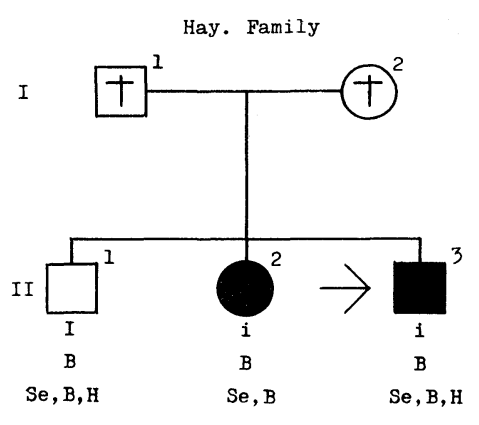

Fig. 3

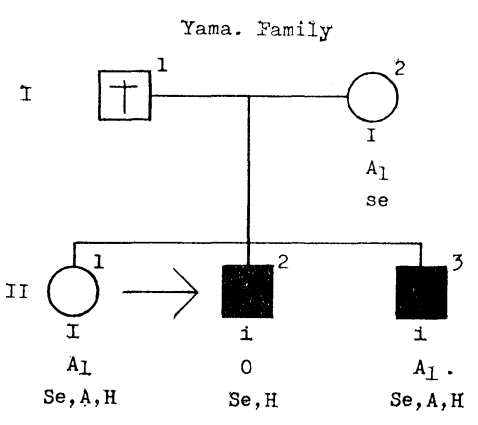

Fig. 4

Table I. The Lod Scores for the Families Sug., Oka., Hay., and Yama.*)

\begin{tabular}{|c|c|c|c|c|c|c|c|}
\hline & & \multicolumn{6}{|c|}{$\theta$, the recombination fraction } \\
\hline & & 0 & 0.05 & 0.1 & 0.2 & 0.3 & 0.4 \\
\hline \multirow[t]{2}{*}{ Sug. } & $z_{3}$ & .977 & .846 & .713 & .452 & .221 & .058 \\
\hline & $\mathrm{e}_{3}$ & -.009 & -.010 & -.009 & -.006 & -.003 & -.001 \\
\hline \multirow[t]{2}{*}{ Oka. } & $z_{3}$ & .852 & .735 & .618 & .389 & .189 & .050 \\
\hline & $\mathrm{e}_{3}$ & .011 & .005 & .002 & -.001 & -.001 & .000 \\
\hline \multirow[t]{2}{*}{ Hay. } & $\mathrm{z}_{3}$ & .727 & .625 & .523 & .327 & .158 & .042 \\
\hline & $e_{3}$ & .063 & .044 & .030 & .013 & .005 & .001 \\
\hline \multirow[t]{2}{*}{ Yama. } & $\mathrm{z}_{3}$ & .727 & .625 & .523 & .327 & .158 & .042 \\
\hline & $\mathrm{e}_{3}$ & .063 & .044 & .030 & .013 & .005 & .001 \\
\hline \multirow{2}{*}{\multicolumn{2}{|c|}{$\begin{array}{l}\text { sum lods } \\
\text { antilog }=\text { relative } \\
\text { probabilities }\end{array}$}} & 3.411 & 2.914 & 2.430 & 1.514 & 0.732 & 0.193 \\
\hline & & 2.576 & 820 & 269 & 33 & 5 & 2 \\
\hline
\end{tabular}

*) Kindly scored by Dr. Ruth Sanger.

among these four families, and any consanguineous marriage was denied except Sug. family. These findings reminded us of Renwick's paper $^{2)}$ on the linkage between a congenital cataract locus and the Duffy blood locus. In our families, the members tested other than the propositi's siblings were all normal in both the traits. It thus appears that the congenital cataract found in the four families is 
genetic and recessive. And then, there seems to be a close linkage between the two loci: "i" blood group and a recessive type of congenital cataract, i.e., the affected persons should be homozygous for both gene $i$ and $c(i i, c c)$, while their parents heterozygous for the both $(I i, C c)$, and probably $i$ and $c$ on the same chromosome, if we provisionally designate this recessive gene for the cataract as $c$ and the corresponding normal allele as $C$.

Drs. Ruth Sanger and R. R. Race ${ }^{3)}$ of the Lister Institute, London, took much interest in our findings and gave us valuable advices. In a personal communication, Dr. Race informed us that according to Sanger's calculations on our four families (see Table I), the odds were about 1000 to 1 in favor of linkage between the $I i$ and the cataract locus. But, he also has pointed out that our families are short of information to distinguish between very close linkage of the

Table II. Blood groups data other than ABO

\begin{tabular}{|c|c|c|c|c|c|c|c|c|c|c|c|}
\hline Kindred & Person & $\begin{array}{l}\text { Year } \\
\text { of } \\
\text { Birth }\end{array}$ & MNSs & $\mathrm{P}$ & $\mathrm{Rh}$ & Kell & Lewis & Duffy & Kidd & I & $\mathrm{Xg}$ \\
\hline \multirow{12}{*}{ Sug. } & $I-1$ & 1903 & MNSs & 2 & CcDEe & $\mathrm{kk}$ & $a+$. & $a+$. & $a+$. & + & . \\
\hline & I -2 & 1907 & NNss & 2 & $\mathrm{CcDEe}$ & $\mathrm{kk}$ & $a-$ & $a+$. & $a-$. & + & . \\
\hline & I -4 & 1912 & NNss & 2 & ccDEE & $\mathrm{kk}$ & $a-$. & $a+$. & $a+$. & + & . \\
\hline & II -1 & 1930 & NNss & 2 & ccDEE & $\mathrm{kk}$ & $a-$. & $a+$. & $a+$. & + & . \\
\hline & II -2 & 1932 & MNSs & 2 & $\operatorname{ccDEE}$ & $\mathrm{kk}$ & $a-$. & $a+$. & $a+$. & + & . \\
\hline & II -3 & 1936 & MMss & 2 & CCDee & $\mathrm{kk}$ & $a-$. & $a+$. & $a-$. & + & . \\
\hline & II -5 & 1939 & MNSs & 2 & ccDEE & $\mathrm{kk}$ & $a-$. & $a+$. & $a-$. & - & . \\
\hline & III- $6^{*}$ & 1942 & MNSs & 2 & $\operatorname{ccDEE}$ & $\mathrm{kk}$ & $a-$. & $a+$. & $a+$. & - & . \\
\hline & II -7 & 1944 & MNSs & 2 & CCDee & $\mathrm{kk}$ & $a-$. & $a+$ & $a+$. & + & . \\
\hline & II -8 & 1949 & MNss & 2 & ccDEE & $\mathrm{kk}$ & $a-$. & $a+$. & $a+$. & + & . \\
\hline & III-1 & 1961 & MNss & 2 & CcDEe & $\mathrm{kk}$ & $a-$. & $a+$. & $a+$. & + & . \\
\hline & IIII-2 & 1964 & MNss & 2 & CcDEe & $\mathrm{kk}$ & $a+$ & $a+$. & $a+$. & + & . \\
\hline \multirow{5}{*}{ Oka. } & I -1 & 1902 & NNss & 1 & $\mathrm{CcDEe}$ & $\mathrm{kk}$ & $a-$. & $a+$. & . . & + & . \\
\hline & II -1 & 1937 & MNss & 2 & CcDEe & $\mathrm{kk}$ & $a-$ & $a+$. & . & + & . \\
\hline & II -2 & 1940 & MNss & 2 & ccDEE & $\mathrm{kk}$ & $a-$ & $a+$. & $a-$. & - & . \\
\hline & II -4 & 1945 & MNss & 2 & CCDee & $\mathrm{kk}$ & $a-$. & $a+$. & . & + & . \\
\hline & II $-5^{*)}$ & 1947 & MNss & 1 & $\operatorname{ccDEE}$ & $\mathrm{kk}$ & $a-$ & $a+$ & $a+$. & - & . \\
\hline \multirow{3}{*}{ Hay. } & III -1 & 1909 & MNss & 1 & $\mathrm{CcDEe}$ & $\mathrm{kk}$ & $a-b-$ & $a+b-$ & $a+$. & + & $a+$ \\
\hline & II -2 & 1926 & MNss & 2 & $\mathrm{CcDEe}$ & $\mathrm{kk}$ & $a-b-$ & $a+b-$ & $a+$. & - & $a-$ \\
\hline & II-3*) & 1929 & MNss & 1 & CCDee & $\mathrm{kk}$ & $a-$ & $a+b-$ & . & - & $a-$ \\
\hline \multirow{4}{*}{ Yama. } & I -2 & 1926 & MNss & 2 & $\mathrm{CcDEe}$ & $\mathrm{kk}$ & $a+b-$ & $a+b-$ & $a+$. & + & $a+$ \\
\hline & II -1 & 1947 & MNss & 1 & CCDee & $\mathrm{kk}$ & $a-b-$ & $a+b-$ & $a+$. & + & $a+$ \\
\hline & $\left.I I-2^{*}\right)$ & 1950 & NNss & 2 & $\mathrm{CcDEe}$ & $\mathrm{kk}$ & $a-b-$ & $a+b-$ & $a+$. & - & $a+$ \\
\hline & II -3 & 1955 & MNss & 2 & CCDee & $\mathrm{kk}$ & $a-b-$ & $a+b-$ & $a+$. & - & $a+$ \\
\hline
\end{tabular}

*) Propositus. 
two loci and the pleiotropy of one locus, owing to the absence of recombination.

In order to find out another family in which there occur both "coupling" and "repulsion" phases between the loci of the $I i$ and of the cataract, we have examined 382 pupils of two schools for the blind and the three cataract families found in a hospital, but unfortunately we have not yet encountered any case of " $i$ " blood in a survey of people with bad sight.

Lastly, as was suggested by Race,4) our four families also provided further genetic information about the Ii system itself: they confirmed that the $I i$ locus had not any linkage with the ABO, MNSs, $\mathrm{P}, \mathrm{Rh}$, Kidd or Xg (see Table II).

Acknowledgement. The authors wish to offer their thanks to Dr. R. R. Race and Dr. Ruth Sanger for their kind help in this survey; and to Prof. R. Kimura for his kind revision of this manuscript and to Prof. T. Kikuchi for his constant encouragement.

\section{References}

1) Yamaguchi, H., Okubo, Y., Tomita, T. ,Yamano, H., and Tanaka, M.: Proc. Japan Acad., 46, 889-892 (1970).

2) Renwick, J. H., and Lawler, Sylvia D.: Ann. Hum. Genet., Lond., 27, 67-84 (1963).

3) Sanger, Ruth and Race, R. R.: Personal communication.

4) Race, R. R.: Personal communication. 